\title{
6 Change of state verbs
}

Change of state verbs are one of the prototypical examples of scalar verbs. There are two reasons for this: first, some of the verbs are derived from gradable adjectives, and second, the verbs are result verbs in the sense of Rappaport Hovav \& Levin (2010) and therefore express a change along a scale.

This chapter is organized as follows: in 6.1, I will present a general overview of the class of change of state verbs and distinguish between different subtypes of change of state verbs. Section 6.2 is more closely concerned with argument realization and argument alternations. Scales are the topic of section 6.3, which elaborates on the notion of scalar change and discusses in detail the question whether all change of state verbs lexicalize a scale. A scalar analysis of telicity will be the topic of section 6.4, and I will turn to the discussion of degree gradation of change of state verbs in section 6.5. Finally, a discussion of telicity with regard to verbal degree gradation is provided in 6.6, before I turn to a conclusion in 6.7.

\subsection{Change of state verbs - a general perspective}

Change of state verbs express a change in an attribute of one of the verb's arguments. To be more precise, it is always the referent of the theme argument that undergoes a change in a certain property. In (1) the gap is the theme argument of the verb, which is realized as the subject of the intransitive verb (a) but as the direct object of the transitive verb (b).

(1) a. The gap widened.

b. The earthquake widened the gap.

The dimension of change is specified by the verb. ${ }^{1}$ Widen specifies the property of change as the theme argument's WIDTH, whereas a verb such

The dimension of change is not always specified by the verb. I turn to such cases in chapter 6.3 . 
as stabilize expresses a change in the theme argument's stability. As discussed in chapter 3, Rappaport Hovav \& Levin (2010) classify change of state verbs as result verbs rather than manner verbs. Result verbs express the attainment of a result but do not specify how that result comes about. Taking widen as an example, the verb expresses that the referent of its theme argument increases in width but the manner in which this happens is not specified. The way Rappaport Hovav \& Levin analyze the difference between result and manner verbs is in terms of scalarity. Result verbs express scalar changes, whereas manner verbs express non-scalar changes (cf. the discussion in chapter 3). A scalar change can be explicated as a change progressing along a certain scale. I will discuss the scalarity of change of state verbs in more detail in 6.3; for the moment it suffices to assume that change of state verbs lexically encode a scale at which they measure the change of the referent of the theme argument.

The changes expressed by these verbs can be classified in several respects: (i) they can be lexically classified with respect to the kind of change expressed by the verb, (ii) they can be distinguished with respect to the opposition between extensional and intensional changes and finally, (iii) they can be aspectually classified in terms of durativity and telicity. The verbs can also be classified with respect to the lexical specification of the scale. I will discuss this point in detail in section 6.3. Levin (1993) proposes a lexical classification of changes as she puts forward a distinction of lexical subclasses of change of state verbs. Among others, she distinguishes the following classes: 'break verbs,' 'bend verbs,' 'cooking verbs' and 'verbs of entity-specific changes of state.' Break verbs, for example, describe a change in the material integrity of the theme argument (Levin, 1993, 242), whereas bend verbs denote a change in the shape of the referent of the theme argument. ${ }^{2}$ Verbs of entity-specific changes are not so much classified by expressing a certain kind of change but rather by imposing strong selectional restrictions on their theme arguments. One example is the verb blossom, which is restricted to plants.

The classification discussed above applies to verbs as such, but the opposition extensional vs. intensional changes applies to uses of verbs.

This is merely a partial classification of dimensions of change. A more extensive typology of dimensions encoded in (stative dimensional) verbs can be found in Gamerschlag (2014). 
Verbs such as steigen 'rise' have two different uses, which are called 'extensional' and 'intensional' Montague (1973); Löbner (1979, 1981). Example (2a) is an extensional use of steigen, whereas in (2b) the verb is used intensionally. In the extensional use a change in a single dimension of the referent of the theme argument is expressed. In (2a) this is the HEIGHT of the balloon. Steigen - in its extensional use - expresses an upward motion along a vertical path.
a. Der Ballon steigt.
the balloon rises
'The balloon is rising.'
b. Die Temperatur steigt.
the temperature rises
'The temperature is rising.'

In the intensional use, the respective dimension of change is specified by a functional noun like Temperatur 'temperature' in (2b). Although in (2a) only a partial change of the referent of the theme argument is predicated - the only relevant change of the balloon is the height of his position a total change of the referent of the theme argument is expressed in the intensional use of steigen. In the case of intensional verbs the subject argument cannot be replaced salva veritate by an expression with the same reference. Die Temperatur in (2b) cannot be replaced by an expression that refers to the referent of the subject to a specific time point, which is a specific degree on the temperature scale, as shown in (3). On the other hand, it is possible to replace the subject referent of the extensionally used verb with an expression that has the same reference as in (4).

(3) \#26 Grad Celsius steigen.

26 degrees Celsius rise

'26 degrees Celsius are rising.'

(4) Das Gefährt der Brüder Montgolfier steigt.

the vehicle the brothers Montgolfier rises

'The vehicle of the Montgolfier brothers is rising.'

(Fleischhauer \& Gamerschlag, 2014, 33)

Verbs such as German steigen can be considered as change of state verbs only in their intensional uses. If they are used extensionally, they have to 
be conceived as verbs of directed motion that express a directed change of position. In their motion sense, i.e., the extensional use, these verbs fully specify the dimension of the positional change. But it is the intensional use which requires an external specification of the dimension, as in (2b), in which the noun Temperatur indicates that the change progresses along the temperature scale.

The contrast between extensional and intensional uses of change of state verbs is discussed less often in the literature than aktionsart-related distinctions between change of state verbs. All change of state verbs are dynamic and express a directed change, but they differ with respect to whether this change is temporally extended (durative) or whether it is punctual. Beavers (2008); Rappaport Hovav (2008) and Rappaport Hovav \& Levin (2010) argue that the contrast between durative and punctual change of state verbs is reflected in their scales. Durative change of state verbs are related to multivalue scales, whereas punctual ones express changes on two-point scales. Two-point scales merely consist of two degrees which form a contradictory pair such as 'alive' and 'dead' in the case of the German achievement predicate sterben 'die.' The values of multivalue scales form a set of contrary degrees which consists of at least three values.

It is a defining feature of achievements and accomplishments that they express telic predications. Degree achievements, the term goes back to Dowty (1979), form a distinct subclass of change of state verbs which display variable telicity like English cool. The English verb cool is compatible with time-frame and time-span adverbials, as the example in (5a) shows. In its telic reading in (5a) cool entails that the soup became cool, whereas in the atelic reading it only entails that the soup got cooler. ${ }^{3}$ Some degree achievements are even basically atelic like grow in (5b) which does not license the in-adverbial (cf. Dowty 1979 and Hay et al. 1999 among others for a discussion of aspectual properties of degree achievements.).

a. The soup cooled for/in an hour. (Hay et al., 1999, 127)

b. \#The child has grown in one year.

Languages differ with regard to aspectual properties of degree achievements like English cool. Kardos $(2012,111)$ states, for example, that in Hungarian the corresponding verb only has an atelic reading; the telic reading requires an explicit delimitation of the event. 
Degree achievements display variable telicity, like incremental theme verbs. ${ }^{4}$ But they differ from incremental theme verbs as it is not the referential properties of the theme argument that determine telicity (cf. Dowty 1979; Levin \& Rappaport Hovav 2005; Kennedy \& Levin 2008; Kennedy 2012). If an incremental theme argument has cumulative reference, the incremental theme predication is atelic, and if it shows quantized reference, the whole predication is telic (cf. Verkuyl 1972; Mourelatos 1978; Bach 1986; Krifka 1986, 1998; Filip 1999, 2000). The incremental theme argument in (6a) is a singular count noun, which has a quantized reference, therefore the predication is telic. We get an atelic predication in (6b) where the incremental theme argument is a mass noun that has cumulative reference (cf. Krifka 1991 for a discussion of different properties of count and mass nouns). A/telicity of degree achievements like cool is not affected by the referential properties of the theme argument as (5a) illustrates. The theme argument is explicitly quantized by the use of the definite article, but irrespective of this fact the verb only licenses an atelic reading.

(6) a. Paul ate an/the apple in ten minutes.

b. \#Paul ate soup in ten minutes.

With respect to degree achievements, telicity is dependent on whether the extent of the change is specified or not (Hay et al. 1999; Levin \& Rappaport Hovav 2005; Kennedy \& Levin 2008; Fleischhauer 2013). In (7a), it is an unspecified change which leads to an atelic interpretation, whereas the measure phrase five degrees specifies the extent of the change in (b) and this results in a telic interpretation.

(7) a. Sandy warmed the solution for three minutes.

b. Sandy warmed the solution five degrees in three minutes.

(Rappaport Hovav \& Levin, 2005, 280)

In English, there is no difference between the telic and the atelic use of the verb. In (7b) it is merely the measure phrase that 'marks' telicity. In other languages, such as Mparntwe Arrernte, the contrast between a telic and an atelic predication is explicitly marked at verb level. In the atelic reading in

Deo et al. (2013) argue that change over time should be seen as an instance of obtaining a value difference, which also allows for capturing extent readings of degree achievements like in The trail narrowed at the summit (Deo et al., 2013, 98). 
(8a), -irre marks the process of getting colder, whereas -arle in (b) indicates the termination of the process, i.e., reaching the endpoint.

(8) Mparntwe Arrernte (Australian; Wilkins 1989 cited after Van Valin 2005, 43)
a. Ayenge irrernt-irre-ke.
1sG.NOM cold-PROC-PST
'I got colder/cooler/*cold.'
b. Ayenge irrernte-arle-irre-ke.
1SG.NOM cold-RES-PROC-PST
'I got cold.'

Telic and atelic change of state verbs - or uses of change of state verbs as in (5a) - differ with regard to their truth conditions. The telic ones entail the reaching of an endpoint (telos) and in languages such as English and German the result state is often denoted by the positive form of an adjective (9a). Atelic change of state verbs equal comparatives in their truth conditions and the result state is often denoted by the comparative form of an adjective (9b).

a. $\quad$ The soup cooled in an hour. $\rightarrow$ The soup got cool.

b. The soup cooled for an hour. $\rightarrow$ The soup got cooler.

German shows a morphological reflex of this distinction, since many deadjectival degree achievements, but not all, are derived from the comparative form of the adjective. Table 12 lists some deadjectival degree achievements, the first three verbs in the table are derived from the comparative form of their adjectival base, whereas the later three are derived from the positive form. ${ }^{5}$ Irrespective of the adjectival base, all degree achievements in table 12 show comparative truth conditions, i.e., merely indicating that a change occurred without entailing the reaching of a specific endpoint. Also Bobal$\mathrm{ijk}(2012,181)$ states that "variable telicity is not a function of the presence or absence of comparative morphology."

$5 \quad$ Bobalijk (2012) shows that if a language has suppletive comparative forms, deadjectival change of state verbs are derived from the suppletive comparative stem and not from the positive stem. An English example is bad - worse - worsen and not * badden. Also cf. Kriz (2011, 51f.) for a discussion of different derivational patterns for deadjectival change of state verbs in German and English. 


\begin{tabular}{|l|l|l|}
\hline $\begin{array}{l}\text { Deadjectival degree } \\
\text { achievement }\end{array}$ & $\begin{array}{l}\text { Positive form of } \\
\text { base adjective }\end{array}$ & $\begin{array}{l}\text { Comparative form } \\
\text { of base adjective }\end{array}$ \\
\hline vergrößern 'enlarge' & groß 'tall' & größer 'taller' \\
\hline verkleinern 'diminish' & klein 'small' & kleiner 'smaller' \\
\hline verbreitern 'broaden' & breit 'broad' & breiter 'broader' \\
\hline $\begin{array}{l}\text { verteuern 'increase in } \\
\text { price' }\end{array}$ & teuer 'expensive' & $\begin{array}{l}\text { teurer 'more } \\
\text { expensive' }\end{array}$ \\
\hline vertiefen 'deepen' & tief 'deep' & tiefer 'deeper' \\
\hline verengen 'narrow' & eng 'narrow' & enger 'narrower' \\
\hline
\end{tabular}

Table 12: Deadjectival degree achievements and their corresponding adjectival bases.

I will use the term 'accomplishment' for all telic uses of change of state verbs, irrespective whether the verb also has an atelic use or not. The term 'degree achievement' will be used for atelic uses of change of state verbs (this differs from the use of the notion of 'degree achievement' in the literature as the term is commonly used to refer to change of state verbs that are either atelic or show variable telicity.). Paraphrases for accomplishments and degree achievements are given in (10). An accomplishment like open can be paraphrased as become open, whereas a degree achievement like grown is paraphrased is become taller. The comparandum, in the case of degree achievements, is the initial size of the argument of the verb and not the size of some other entity. Note that the paraphrases are only intended to capture the inchoative reading of change of state verbs, causality will be discussed in the next section.
a. Accomplishment: Become $\mathrm{ADJ}_{\mathrm{POS}}$
b. Degree Achievement: Become ADJ

The distinction between degree achievements and accomplishments will turn out to be relevant for the discussion of degree gradation of change of state verbs. Therefore, I will discuss telicity in more detail in section 6.4. In the next section, I first will turn to a discussion of the argument realization of change of state verbs. 


\subsection{Argument realization}

In German, change of state verbs basically show the argument realization patterns in (11). There are intransitive change of state verbs like wachsen 'grow' (11a), which do not have a transitive variant with the same root (b). There are also change of state verbs which are basically transitive, as verbreitern 'widen' in (c).
a. Das Kind wächst.
the child grows
'The child is growing.'
b. ${ }^{*}$ Die Eltern wachsen das Kind.
c. Das Erdbeben verbreitert den Riss. the earthquake widens the crack 'The earthquake is widening the crack.'

The single argument of intransitive change of state verbs is a theme argument. The theme denotes the participant that is affected by the change. Transitive change of state verbs realize the theme argument as direct object, whereas the subject argument is semantically a causer or the cause. The causer is responsible for bringing about the change in the theme argument. Verbs such as wachsen do not have a causative variant; Levin \& Rappaport Hovav (1995) argue that wachsen and other verbs like it express an internally caused event. Verbreitern and other transitive change of state verbs denote externally caused events. In such a case, an event participant who is distinct from the referent of the theme argument is responsible for initiating the event. In the case of internally caused events, it is a property of the referent of the theme argument, for example, a biological predisposition, which causes the event. For a critical examination of this analysis see, for example, McKoon \& MacFarland (2000). The event structural representation of both types of change of state verbs is shown in (12).
a. externally caused change of state verb $\left[\mathbf{d o}^{\prime}(\mathrm{x}, \emptyset)\right]$ CAUSE [BECOME pred'(y)]
b. internally caused change of state verb BEcome pred'(y) 
The distinction between internally and externally caused change of state verbs is, among other things, intended to explain which verbs participate in the causative/inchoative alternation and which do not. Internally caused change of state verbs are always intransitive, whereas externally caused change of state verbs show up in a transitive argument realization pattern. Many causative change of state verbs also have a derived inchoative use, in which the causer is not expressed anymore and the theme argument is realized as the subject of the verb. In German, two different derivational patterns can be found for derived inchoative change of state verbs. We have zero derivation in (13a) and (b); neither the inchoative nor the causative use of schmelzen is explicitly marked. This kind of derivation is the usual one in English, whereas in German a marking of the derived inchoative verb by the reflexive sich is more common. ${ }^{6}$ The examples in (11c) vs. (13c) illustrate the derivation of the inchoative verb from the causative by means of reflexive marking.
a. Der Käse schmilzt. the cheese melts
'The cheese is melting.'
b. Die Sonne schmilzt den Käse.
the sun melts the cheese
'The sun is melting the cheese.'
c. Der Riss verbreitert sich.
the crack widens REFL
'The crack is widening.'

Russian, as well as French, also derives inchoative change of state verbs from causative ones. French uses a reflexive pronoun like German to mark the inchoative verb (14). Russian does not use a reflexive pronoun, but instead the reflexive affix -sja is attached to the verb to mark the derived inchoative verb (15). ${ }^{7}$
a. Le tremblement de terre est en train d' élargir la fissure. the earthquake PROG widen the crack 'The earthquake is widening the crack.'

6 Cf. Haspelmath (1993) for an overview of different strategies for the realization of causative/inchoative verb pairs.

7 Beside the bounded form, Russian also has a free reflexive pronoun. The free form is not used for marking the causative-inchoative alternation, however. 
b. La fissure est en train de s'élargir.

the crack PROG REFL=widen

'The crack is widening.'

a. Mal'čik plavit syr.

boy melts cheese

'The boy is melting cheese.'

b. Syr plavit-sja.

cheese melt-REFL

'The cheese is melting.'

Different analyses for the causative/inchoative alternation have been proposed in the literature. The decausativation analysis assumes that the inchoative verb is derived from the causative one by means of a decausativizing process. In this case, the causal subevent is deleted from the event structure of the verb and at the same time the verb is detransitivized. Such an analysis is, for example, assumed by Löbner $(2013,138)$. A different view is that the inchoative verb is derived from the causative one by existential binding of the causer. In this case, the causative subevent is not deleted from the event structure of the verb. This results in the derivation of an intransitive verb, which otherwise does not differ semantically from the causative one. Such an approach is advocated by, for example, Levin \& Rappaport Hovav (1995). ${ }^{8}$ A third account is the reflexivization analysis of Koontz-Garboden (2009). According to this account, it is assumed that the reflexive pronoun really has a reflexive interpretation such that the causer and theme argument are taken to be coreferential. ${ }^{9}$ Beavers \& Zubair $(2013,32 \mathrm{f}$.) state that a non-agentive causer cannot act on itself and in such a case we get the reading that something internal to the theme argument causes its change. Hence, we have a derived internally caused change of state interpretation. If the causer is agentive, then a plain causative use of the change of state verb remains, as in (16). The verb allows a reflexive marking, but it does not derive an inchoative reading. Rather the causer is interpreted as acting on itself. For a critical discussion of this approach

$8 \quad$ Rappaport Hovav \& Levin (2012) argue against their 1995 analysis and reject the view that inchoative change of state verbs are derived from causative ones by a lexical rule that existentially binds the causer.

9 Cf. Koontz-Garboden (2009, 83ff.) for a formal representation of the reflexivization approach based on Chierchia's (2004) reflexive operator. 
see Horvath \& Siloni (2011) and the replies in Beavers \& Zubair (2013) and Beavers \& Koontz-Garboden (2013).

Der Mann hat sich getötet.

the man has REFL killed

'The man killed himself.'

Koontz-Garboden's approach does not apply to languages such as English, which do not make use of a reflexive marking in deriving inchoative change of state verbs. An account of the causative/inchoative alternation needs to explain why some verbs, such as English sterilize, do not alternate (17).

a. The nurse sterilized the instruments.

b. $\quad$ *The instruments sterilized.

(Levin \& Rappaport Hovav, 1995, 95)

Heidinger (2012) claims - based on Haspelmath (1993) - that only verbs referring to spontaneously occurring events can participate in the causative/inchoative alternation. Changes that cannot be considered to occur spontaneously - i.e. they can also occur without an external causation - can only be expressed by causative verbs. Rappaport Hovav \& Levin (2012) claim that if a verb requires an agentive causer, it cannot participate in the causative/inchoative alternation. The exact analysis of the nature of the causative/inchoative alternation does not matter for a discussion of degree gradation of change of state verbs and therefore I will stay uncommitted about it. Relevant for causative/inchoative verbs is that both variants require the realization of the theme argument. Rappaport Hovav (2008) uses this as one of the defining criteria for scalar change verbs (see chapter 3.3 and next section). As was previously discussed, the explanation she provides is that the entity undergoing a scalar change has always to be realized overtly in a sentence. Crucially, the theme argument cannot be deleted by an argument alternating process. Intensionally used verbs deviate from the argument realization pattern observed above. As (18a) shows, the theme argument Buch 'book' is realized as the possessor of the scale-denoting noun Preis 'price.' Fleischhauer \& Gamerschlag $(2014,41)$ write that " $[\mathrm{t}]$ aken literally, the change denoted by steigen is predicated of the referent of the subject Preis which therefore can also be characterized as a theme. However, the theme relevant to Rappaport Hovav's deletabil- 
ity criterion is contributed by the possessor DP which refers to the participant whose property is measured on the scale." Preis does not refer to that participant. Rather, it introduces the scale on which the change is predicated. Hence, it can be considered as a scale-denoting noun and the contrast between (18b) and (c) shows, it is the theme argument but not the scale-denoting noun that can be deleted.
a. Der Preis des $\quad$ Buchs $_{\text {Theme }}$ ist gestiegen. the price of.the book.GEN is risen
'The price of the book has risen.'
b. Der Preis ist gestiegen.
the price is risen
'The price has risen.'
c. \#Das Buch ist gestiegen.
the book is risen
(Fleischhauer \& Gamerschlag, 2014, 38)

Following Löbner (1979, 1985, 2011a), scale-denoting nouns such as Preis 'price' or Temperatur 'temperature' are functional nouns. Functional nouns are relational, which means that they take one or more arguments and, due to functionality, provide a unique mapping between the referent of the noun and its argument(s). In the case of Preis, it takes the argument Buch 'book' in (18a) and assigns it a unique value on the price scale. This value is the referent of the noun Preis. Not all functional nouns are scalar: mother, for example, is a functional noun, too. In (19) it expresses a unique relation between fohn and a further individual, who is the mother of John. The 'mother of'-relation between John and his mother is unique but the value assigned is not a degree on a scale.

\section{the mother of fohn}

In the case of Preis, the noun assigns a price value to the object it takes as possessor argument. Fleischhauer \& Gamerschlag analyze such scaledenoting nouns as measure functions; they are functions from individuals to degrees. A semantic representation for such scalar functional nouns is shown in (20). Preis is represented as the measure function PRICE that maps individuals onto price degrees. The index indicates the parameters (dimension, set of degrees and linear order) of the scale onto which the 
concept maps the individual. The $x$ argument is saturated by the possessor argument of the functional noun.

$$
\text { Preis 'price' } \lambda \mathrm{x} \lambda \text { t.PRICE }\langle\text { Price, } \text { PriceDeg., },>\rangle(\mathrm{x}, \mathrm{t})
$$

(Fleischhauer \& Gamerschlag, 2014, 43)

The argument of a functional noun can be omitted if it is recoverable from context (18b). This explains why the theme argument of intensionally used verbs can be deleted. Intensionally used verbs also undergo the possessorsubject alternation (cf. Levin 1993, 77f., also Löbner 1979) as shown in (21) taken from Fleischhauer \& Gamerschlag $(2014,41)$. In (21b) the possessor argument is realized as the subject of the sentence and the functional noun is realized within a PP.
a. Der Preis des Buchs ist gestiegen. the price of.the book.GEN is risen 'The price of the book has risen.'
b. Das Buch ist im Preis gestiegen. the book is in.the price risen 'The book has risen in price.'

Change of state verbs like wachsen 'grow' differ in argument realization from intensionally used verbs (22). The theme argument cannot be realized as the possessor argument of a scale-denoting noun (a) and the possessorsubject alternation is not possible with such verbs (b). As (23) shows, this holds similarly for the extensional uses of verbs like steigen.
a. *Die Größe des Kindes wächst. the size of.the child.Gen grows
b. ${ }^{*}$ Das Kind wächst in der Größe. the child grows in the size (Fleischhauer \& Gamerschlag, 2014, 42)

(23) a. Der Balloon steigt.

the balloon rises

'The balloon is rising.'

b. *Die Höhe des Balloons steigt. the height of.the balloon.GEN rises 
c. ${ }^{*}$ Der Balloon steigt in der Höhe. the balloon rises in the height

A reason why wachsen rejects the realization of a scale-denoting noun is that the verb itself specifies a scale, which is not the case with intensionally used steigen. In the next section, I will discuss the lexicalization of scales in more detail and argue that verbs like intensional steigen are scalar even if the scale is determined by its subject argument.

\subsection{Scalar changes and the lexicalization of scales}

As mentioned above and discussed in detail in chapter 3, Rappaport Hovav \& Levin (2010) classify change of state verbs as result verbs. Result verbs express scalar changes, which distinguishes them from manner verbs which express non-scalar changes. A central assumption made by Rappaport Hovav \& Levin is that result verbs lexicalize a scale along which the respective change is measured. This claim can be formulated as in (24), which Fleischhauer \& Gamerschlag (2014) call the 'strong version of the lexicalization of scales hypothesis.' The reason why it is called a 'strong version' is that it requires that the verb lexically specifies all scale parameters. The weaker version of this hypothesis will be presented below.

(24) Lexicalization of scales (strong version): If a change of state verb lexicalizes a scale, all scale parameters are specified in the lexical meaning of the verb.

(Fleischhauer \& Gamerschlag, 2014, 33)

There are clear cases for which the strong version of the lexicalization of scales hypothesis seems to be true. These are, for example, the German change of state verbs verteuern 'increase in price' and wachsen 'grow.' The scale parameters lexicalized by these verbs are shown in (25).

a. verteuern 'increase in price' $\Delta$ : PRICE, D: price degrees, R: $<^{10}$

b. wachsen 'grow' $\Delta$ : SIzE, D: size degrees, R: <

To repeat the abbreviations which are taken from Kennedy \& McNally's (2005a) analysis of scales: ' $\Delta$ ' is the measurement dimension, ' $D$ ' is the set of degrees and ' $R$ ' is the linear order of these degrees (cf. section 2.2). 
Taking verteuern as an example: the verb specifies the dimension $(\Delta)$ of change as PRICE. The dimension restricts the values to price values and there is a linear ordering relation for the values of that scale $(<)$. The scale is inherited from the base adjective teuer 'expensive' from which the verb is derived. Since wachsen 'grow' is not derived from an adjective, it cannot be said that the lexicalization of all scale parameters is only due to the fact that these parameters are already specified by the base adjective.

Other verbs are more problematic for the strong lexicalization hypothesis. First, intensionally used verbs like steigen 'rise' provide a problem for the hypothesis since such verbs require a scale-denoting noun to specify the respective scale of change. As the examples in (26) show, the respective scale of change is dependent on the nominal argument and varies in all three sentences ('pressure' in (a), 'price' in (b) and 'temperature' in (c)). The verb is underspecified regarding the scale parameters and depends on the noun that specifies the scale of change.
a. Der Druck steigt. the pressure rises
'The pressure is rising.'
b. Der Preis steigt. the price rises
'The price is rising.'
c. Die Temperatur steigt.
the temperature rises
'The temperature is rising.'

Second, there are verbs such as German verfärben 'change color' or verformen 'form into' which specify a dimension of change as well as possible values but do not impose a linear order on them. Verfärben expresses a change in the dimension COLOR and specifies that the respective values are color values. Although the color space is structured Gärdenfors (2000), colors are not linearly ordered and hence do not form a scale. Rather, verfärben expresses an undirected change through color space, which is compatible with a change from, for example, red to blue or blue to red. Rappaport Hovav \& Levin report a similar case in the domain of motion verbs. They write with regard to the verbs cross and traverse: "Although they [cross and traverse] lexically specify motion along a path defined by a particular axis on the ground, the direction of motion along this path is not lexically spec- 
ified and, hence, they do not impose an ordering on the points on the path. [... the verb cross is equally applicable whether a traversal of the England Channel is from England to France or from France to England" (Rappaport Hovav \& Levin, 2010, 30). The verbs cross and traverse are similar to verfärben in expressing an arbitrary and undirected change in a specified dimension. Rappaport Hovav \& Levin conclude that cross and traverse are non-scalar change verbs. This raises the question as to whether verfärben, as well as intensionally used change of state verbs, qualify as scalar change verbs or not.

In chapter 3.3, different properties that are characteristic of scalar change verbs but not of manner verbs have been discussed. Based on Rappaport Hovav (2008) it has been shown that scalar change verbs are restricted to result-XPs that are compatible with the lexicalized scale. Also scalar change verbs do not allow omission of the theme argument. Piñon (2005) further mentions that only scalar change verbs can combine with gradually without requiring coercion. Non-scalar change verbs need to be coerced towards a scalar change reading to combine with gradually. ${ }^{11}$ A case in point, discussed by Piñon, is He gradually loves her, which means that the referent of the subject argument gradually fell in love with someone. Also plural arguments, as in He gradually rescued the children, license the addition of gradually. In this case, a gradual affection of the plural referents is expressed (cf. Piñon 2005 for a deeper discussion of these examples). In (27), it is shown that the German adverb graduell 'gradually' can combine with a scalar change verb (verteuern) but not with non-scalar change verbs like essen 'eat' and schreien 'cry.' ${ }^{12}$
a. Das Apartment hat sich graduell verteuert. the apartment has REFL gradually increase.in.price 'The apartment has gradually increased in price.'
b. ${ }^{*}$ Das Kind hat graduell gegessen. the child has gradually eaten
c. *Das Kind hat graduell geschrien. the child has gradually cried

\footnotetext{
$11 \quad$ Cf. Gawron $(2009,7)$ for a discussion of the combination of gradually with stative verbs.

12 German also has the adverb allmählich, meaning gradually, but this also has a temporal interpretation and is therefore not used in this test construction.
} 
As the following examples show, both verfärben and steigen show the same properties as scalar change verbs do. The examples in (28) show that verfärben and steigen are restricted with respect to admissible result-XPs. Verfärben only allows for color adjectives as result predicates, whereas in the case of steigen the result-XP has to be compatible with the scale denoted by the functional noun.
a. Das Laub verfärbt sich rot/\#nass/ \#alt/ \#welk. the leave change.color REFL red wet old limp 'The leaves change color to red/\#wet/\#old/\#limp.'
b. Der Preis des Buchs steigt auf 10 Euro/ \#neu/ \#rot. the price of.the book rises to 10 euro new red 'The price of the book is rising to 10 euros/\#new/\#red.' (Fleischhauer \& Gamerschlag, 2014, 37)

Deletion of the theme argument is not possible in the case of verfärben; as shown in (29). Intensionally used verbs differ with regard to argument realization and allow the deletion of the theme argument (cf. section 6.2).
a. Der Regen Causer verfärbt die Hausfassade $_{\text {Theme }}$. the rain changes.color the house.front 'The rain changes the color of the front of the house.'

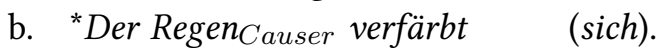 the rain changes.color REFL

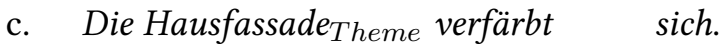 the house.front changes.color REFL 'The color of the front of the house changes.' (Fleischhauer \& Gamerschlag, 2014, 38)

Fleischhauer \& Gamerschlag $(2014,38)$ cite the examples in (30) to show that both verfärben and steigen can combine with graduell. Neither verfärben nor steigen requires coercion to combine with the adverb.

a. [...] eine Beschichtung [...], die sich bei Einwirkung eines Desinfektionsmittels auch graduell verfärbt [...]..$^{13}$

'[...] a surface coating which gradually changes color if impacted by germicide [...].'

13 http://www.patent-de.com/20010913/DE10065941A1.html (15.7.2012) 
b. Juncker sagte dazu am Rande des Treffens, der Euro-Kurs habe sich nicht "brutal" nach oben bewegt, er sei graduell gestiegen. ${ }^{14}$ 'On this point, Juncker said in the margins of the meeting that the Euro exchange rate has not moved "dramatically" upwards, it has risen only gradually.'

The data discussed above reveal that verfärben and steigen exhibit the properties of scalar change verbs. Hence, these verbs qualify as scalar and therefore lexicalize a scale. But this assumption is in conflict with the strong version of the lexicalization of scales hypothesis proposed in (24). Instead, the data warrant a weaker version of the lexicalization assumption, such as the one proposed in (31).

(31) Lexicalization of scales (weak version): A change of state verb lexicalizes a scale, even if one or more of the scale parameters remain unspecified in the meaning of the verb.

(Fleischhauer \& Gamerschlag, 2014, 34)

The weak version allows for an underspecification of scale parameters in the lexical semantics of the verb. Table 13 provides a typology of scalar underspecification of change of state verbs.

\begin{tabular}{|l|l|l|}
\hline Verb(s) & $\begin{array}{l}\text { Unspecified in the } \\
\text { verb meaning }\end{array}$ & $\begin{array}{l}\text { Specified in the verb } \\
\text { meaning }\end{array}$ \\
\hline $\begin{array}{l}\text { verteuern 'increase in } \\
\text { price', wachsen 'grow' }\end{array}$ & all scale parameters \\
\hline $\begin{array}{l}\text { verfärben 'change } \\
\text { color', verformen } \\
\text { 'form into' }\end{array}$ & order of values & dimension, values \\
\hline $\begin{array}{l}\text { steigen 'rise', fallen } \\
\text { 'fall', verändern } \\
\text { 'change' }\end{array}$ & all scale parameters & \\
\hline
\end{tabular}

Table 13: Typology of scalar (under)specification (Fleischhauer \& Gamerschlag, 2014, 39).

14 http://m.faz.net/aktuell/wirtschaft/wirtschaftspolitik/wirtschaftspolitik-eurolaender-verpflichten-sich-zum-sparen-1435278.html (15.7.2012) 
Verbs such as verteuern and wachsen lexically specify all scale parameters, whereas verfärben and verformen only specify the dimension and values. The third type of verbs, which include verbs such as steigen, fallen 'fall' and verändern 'change,' leave all scale parameters underspecified.

There is a further property distinguishing steigen from fallen on the one hand and verändern on the other. The first two verbs lexically specify the direction of change, whereas verändern does not. As shown in (32) and (33), steigen is only compatible with an increase of values. In the case of (32), the temperature degree has to increase and cannot decrease. It is the opposite for fallen in (33), which is only compatible with a decrease in temperature.

$$
\begin{aligned}
& \text { Die Temperatur steigt. } \\
& \text { the temperature rises } \\
& \text { 'The temperature is rising.' } \\
& \rightarrow \text { The temperature is increasing. } \\
& \rightarrow \text { The temperature is decreasing. }
\end{aligned}
$$

$$
\begin{aligned}
& \text { Die Temperatur fällt. } \\
& \text { the temperature falls } \\
& \text { 'The temperature is falling.' } \\
& \rightarrow \text { The temperature is decreasing. } \\
& \rightarrow \text { The temperature is increasing. }
\end{aligned}
$$

Verändern on the other hand is compatible with an increase as well as a decrease of the temperature degree (34). The verb only indicates that there is some difference in temperature but leaves open whether it gets warmer or cooler.

$$
\begin{aligned}
& \text { Die Temperatur verändert sich. } \\
& \text { the temperature changes REFL } \\
& \text { 'The temperature is changing.' } \\
& \rightarrow \text { The temperature is increasing. } \\
& \rightarrow \text { The temperature is decreasing. }
\end{aligned}
$$

Considering direction of change as independent from the three scale parameters, which can be justified by the fact that (32) and (33) differ only with respect to the direction of change but not with respect to the scale, we get a fourth parameter which can be lexically specified by change of 
state verbs. This produces the revisited table in 14, which adds the direction of change as a further parameter lexically (under)specified in change of state verbs. Most change of state verbs seem to be fully specified with regard to all scale parameters and the set of verbs totally underspecified with regard to all scale parameters and the direction of change seems to be rather restricted. An open question is whether the typology in table 14 covers all types of scalar underspecification; so far, some possible types do not seem to be attested, such as verbs specifying all scale parameters but leaving the direction of change underspecified. Also, there do not seem to be any verbs which specify the dimension of change but not the set of values. This could be due to logical reasons as the set of values does not seem to be independent from the dimension of change. But the first type does not seem to be logically excluded, so it is an empirical question whether some language lexicalizes such verbs.

\begin{tabular}{|l|l|l|}
\hline Verb(s) & $\begin{array}{l}\text { Unspecified in the } \\
\text { verb meaning }\end{array}$ & $\begin{array}{l}\text { Specified in the verb } \\
\text { meaning }\end{array}$ \\
\hline $\begin{array}{l}\text { verteuern 'increase in } \\
\text { price', wachsen 'grow' }\end{array}$ & $\begin{array}{l}\text { all scale parameters, } \\
\text { direction of change }\end{array}$ \\
\hline $\begin{array}{l}\text { verfärben 'change } \\
\text { color', verformen } \\
\text { 'form into' }\end{array}$ & order of values & $\begin{array}{l}\text { dimension, values, di- } \\
\text { rection of change }\end{array}$ \\
\hline $\begin{array}{l}\text { steigen 'rise', fallen } \\
\text { fall' }\end{array}$ & all scale parameters & direction of change \\
\hline $\begin{array}{l}\text { verändern 'change' } \\
\text { all scale parameters, } \\
\text { direction of change }\end{array}$ & \\
\hline
\end{tabular}

Table 14: Typology of scalar (under)specification (based on Fleischhauer \& Gamerschlag 2014).

Fleischhauer \& Gamerschlag discuss two strategies for the resolution of scalar underspecification. First, missing scale parameters can be introduced by a scale-denoting noun as is the case with intensionally used change of state verbs. Second, missing scale parameters can be supplied by context. In the following, I will merely concentrate on the first strategy, 
but for contextual issues in the resolution of scalar underspecification see Fleischhauer \& Gamerschlag (2014). Starting with verteuern, the semantic representation of a totally specified change of state verb can be assumed to look like in (35). The representation makes use of the measure function PRICE, which returns a degree on a price scale for some argument $x$ to a certain time. The time is given by the function $\operatorname{BEGIN}(\mathrm{e})$, which returns the first time point of the event denoted by the verb, respectively $\operatorname{END}(\mathrm{e})$ returns the last time point of the event. Basically, the verb expresses an inequality between the degree of $x$ on the price scale at the initial moment of $e$ and the degree of $x$ on the price scale at the final moment of $e$. The bracketed index at the measure function represents the three lexically specified scale parameters.

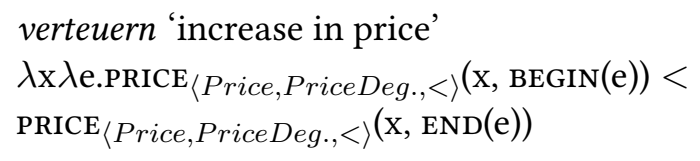

For intensionally used steigen, Fleischhauer \& Gamerschlag (2014, 43) assume the semantic representation in (36). Like verteuern, the verb has two arguments but it differs in the nature of its arguments from the former one. Unlike verteuern, it does not take an individual but rather a measure function $f$ as its argument. Semantically, steigen expresses that the degree delivered by the measure function is higher at the end of the event than it was at its beginning.

$$
\begin{aligned}
& \text { steigen 'rise' } \\
& \left.\lambda \mathrm{f}_{\langle\Delta, D, R\rangle} \lambda \text { e.f(BEGIN(e) }\right)<\mathrm{f}(\operatorname{END}(\mathrm{e}))
\end{aligned}
$$

Since steigen selects for a measure function, it can only combine with scale-denoting nouns, such as Preis 'price.' Based on the discussion in the last section, the semantic representation for functional nouns looks like that in (37). Since the functional noun is relational, it introduces its possessor as an argument.

$$
\begin{aligned}
& \text { Preis 'price' } \lambda \mathrm{x} \lambda \mathrm{t}_{\text {.PRICE }}\langle\text { Price,PriceDeg. },<\rangle \\
& \text { (Fleischhauer \& Gamerschlag, 2014, } 43 \text { ) }
\end{aligned}
$$

By combining (36) and (37) via functional application we get the represen- 
tation in (38) for der Preis des Buchs steigt 'the price of the book is rising.'15 Preis saturates the $f$-argument of the measure function and thereby introduces its own possessor argument. The $x$ argument is the possessor of Preis and is specified by the $\iota$ operator due to the definite article.

(38) der Preis des Buchs steigt 'the price of the book is rising' $\lambda$ e.PRICE $\langle$ Price,PriceDeg., $<\rangle(\iota \mathrm{x}[\operatorname{book}(\mathrm{x})], \operatorname{BEGIN}(\mathrm{e}))<$ $\operatorname{PRICE}_{\langle\text {Price }, \text { PriceDeg. },<\rangle}(\iota \mathrm{x}[\operatorname{book}(\mathrm{x})], \operatorname{END}(\mathrm{e}))$

The representation of fallen and verändern would differ from steigen in (36) mainly in the type of inequality lexically specified, which would be ' $>$ ' for fallen and ' $\neq$ ' for verändern. Additionally, it is not the case that verbs such as verändern always take a scalar noun as their argument but rather that non-scalar functional nouns are possible, too (for a more detailed discussion of this point cf. Fleischhauer \& Gamerschlag 2014).

The semantic representations used above are merely intended to capture the compositional process of scale composition but do not include a principled account of telicity (see Gamerschlag et al. 2014 for a frame-based representation of scale composition). In the next section, I turn to scalar approaches that aim at analyzing (i) variable telicity, (ii) telicity of accomplishments as well as (iii) providing an explanation of the relationship between scalar properties of adjectives and telicity of deadjectival change of state verbs.

\subsection{Scalar analysis of telicity}

Change of state verbs do not behave uniformly with respect to telicity. First, there are strictly telic change of state verbs like open, close and stabilize. Second, there are atelic change of state verbs such as grow and lastly verbs displaying the behavior of both. Such verbs show variable telicity, as demonstrated in (39).

(39) a. The soup cooled for an hour.

b. The soup cooled in an hour. (Hay et al., 1999, 127)

For the sake of simplicity, the event argument will be left unsaturated although the verb is used in a finite form. 
Since Dowty (1979), the semantics of change of state verbs, more specifically the change denoted by these verbs, has been represented by a BECOME operator. In several approaches, refinements of this analysis have been proposed that decompose this operator and more explicitly represented changes as a progression along a scale. One reason for doing so is that verbs such as cool are variable in telicity and do not simply mean Become(cool'), in the sense of 'something changes till it reaches the state of being cool.' Rather, in the atelic reading it simply means 'become cooler than before.'

Borik (2006) distinguishes between the 'end-point approach' and the 'homogeneity approach' of telicity. The end-point approach relates telicity to the reaching of a temporal or other end-point, whereas the homogeneity approach focuses on the referential properties of (a)telic predicates. One special type of 'end-point approaches' are scalar analyses of telicity, such as those by Hay et al. (1999); Caudal \& Nicolas (2005); Beavers (2006, 2008); Kearns (2007); Kennedy \& Levin (2008); Piñón (2008), and others. In such degree-based analyses, the telos is equated with an endpoint on a scale. I will not provide a review of these approaches; rather, I restrict myself to a discussion of the influential work by Hay et al. (1999) and the proposal by Caudal \& Nicolas (2005). ${ }^{16}$ The aim is to introduce a degree-based analysis of telicity and to make the interaction between telicity and verbal degree gradation explicit. A revised degree-based analysis of telicity will be presented in section 6.6.

Telicity of change of state verbs is not dependent on the referential properties of the theme argument. Hay et al. state that telicity of degree achievements (strictly atelic ones as well as those showing variable telicity) depends on the fact whether the change on the scale is bounded or not. Since most degree achievements in English are deadjectival, as Hay et al. $(1999,130)$ state, the semantic core of these verbs is a gradable adjective. Kennedy's (1999a; 1999b) analysis of gradable adjectives is the basis for Hay et al.'s account of deadjectival verbs. They assume that the verb-forming morphology (either a zero form or -en in English) takes a gradable adjective as argument and returns a description of a change of state event. It is essen-

For a review and comparison of different degree-based approaches see Piñón (2008) and Kriz (2011). See Fleischhauer (2013) for a comparison of 'end-point' and 'homogeneous approaches' with respect to degree gradation of change of state verbs. 
tially the function INCREASE that is contributed by the verb-forming morphology. The truth conditions for this function are shown in (40), where $\varphi$ is a gradable adjective meaning and $\mathrm{SPO}(\mathrm{e})$ and EPO(e) are functions that return the beginning, respectively end point of the event.

$$
\llbracket \operatorname{INCREASE}(\varphi)(\mathrm{x})(\mathrm{d})(\mathrm{e}) \rrbracket=1 \text { iff } \varphi(\mathrm{x})(\operatorname{sPO}(\mathrm{e}))+\mathrm{d}=\varphi(\mathrm{x})(\operatorname{EPO}(\mathrm{e}))
$$

(Hay et al., 1999, 132)

(40) states that InCREASE $(\varphi)(\mathrm{x})(\mathrm{d})(\mathrm{e})$ is true, if the degree $\mathrm{d}$ of $x$ in the property expressed by $\varphi$ at the end of the event equals the degree of $x$ at the beginning of the event plus some degree $d .{ }^{17}$ Hence, $d$ represents a difference value that specifies the increase of $x$ with regard to $\varphi$.

The sentences in (41) are now given the representations in ScaleTelicity 4. Causality is ignored in the representation as it does not influence telicity. The degree argument is existentially bound in ScaleTelicity 4 and Hay et al. do not propose a verbal positive morpheme in difference to later work by, for example, Kennedy \& Levin (2008).

a. Kim lengthened the rope.

b. Kim lengthened the rope 5 inches.

(Hay et al., 1999, 130)

a. $\exists e, d[\operatorname{InCREASE}($ long(rope) $)(\mathrm{d})(\mathrm{e})]$

b. $\exists$ e[INCREASE(long)(rope)(5 inches)(e)]

(Hay et al., 1999, 132)

What (a) states is that the length of the rope increases by some amount, whereas in (b) the increase is explicitly bound by the measure phrase 5 inches. If the difference value, the variable $d$, is bounded, a telic predication arises. If it is unbounded, the resulting predication is atelic. This is validated by the examples in (43). The entailment from the progressive to the perfect only holds in (a) but not in (b).

(43) a. Kim is lengthening the rope. $\rightarrow$ Kim has lengthened the rope. (Hay et al., 1999, 127)

b. Kim is lengthening the rope 5 inches. $\nrightarrow$ Kim lengthened the

For degree addition see von Stechow (1984); Rullmann (1995), Hay et al. (1999, 131) among others. 
6.4 Scalar analysis of telicity

rope 5 inches. (Hay et al., 1999, 130) 
The difference value can be bounded in different ways. One way, which is exemplified above, is by using a measure phrase. Another way is by using degree modifiers such as slightly or significantly. Example (44), taken from Hay et al. $(1999,134)$, shows the combination of a degree achievement with the intensifier significantly. As (b) indicates, the graded predication is telic.

(44) a. The independent counsel broadened the investigation significantly.

b. The IC is broadening the investigation significantly. $\rightarrow$ The IC has broadened the investigation significantly.

A degree expression like significantly introduces a standard (minimum) value up to which the change has to progress. Based on such data, Hay et al. refine their explication of the notion of a 'bounded change': "a telic reading of a DA [degree achievement] requires that the difference value specify a lower bound on the degree to which an object must increase in the relevant property over the course of the event. Once this minimal point is reached, the truth conditions for the event description are met" (Hay et al., 1999, 134).

But how does a telic interpretation arise, if there is no measure phrase or degree expression that provides a bound on the difference value? Scale structure is crucial in determining telicity. Degree achievements derived from closed-scale adjectives are by default telic since the scalar endpoint provides a bound on the difference value and the change can progress until the endpoint is reached. If a degree achievement is derived from an openscale adjective, it typically behaves atelically (Hay et al., 1999, 136). The reason is that if there is no endpoint, there is no lexical basis for inducing a bound on the difference value.

Hay et al. and also subsequent work by Kennedy \& Levin (2008) restrict their analysis to degree achievements, basically deadjectival ones. Caudal \& Nicolas (2005) propose a general degree-based analysis of telicity that is not restricted to degree achievements. Their definition of telicity is given in (45). The 'axiom Become,' which is mentioned in (c), defines a homomorphic mapping between a scale and an event such that each part of the event is mapped to a unique degree and vice versa. The temporal order of the event is matched by the order of the degrees (for details cf. Caudal \& Nicolas 2005, 286, 293). The function of BEcome is to measure 
the progression of an event on a scale and to provide a strict mapping between the set of degrees and the event (the mapping between scales and events will be discussed in more detail in chapter 9).

Telicity: A predication is telic if and only if,

(a) it has an associated set of degrees,

(b) a specified maximal degree, and

(c) its verbal predicate satisfies the axiom BECOME.

(Caudal \& Nicolas, 2005, 294)

Following Caudal \& Nicolas, a predication is telic if it expresses a change along a scale that has a maximal degree, i.e., forms a closed scale. Since there is a strict mapping between degrees and parts of an event, the event has to terminate if the maximal scale value is reached. They write: "the set terminal point of an event described by a telic predication is reached when the specified maximal degree is reached too; then the event cannot develop any further" (Caudal \& Nicolas, 2005, 295). Caudal (2005) further states that atelic predications are related to open scales since there is no set terminal point which has to be reached. ${ }^{18}$ Since Caudal \& Nicholas equate the telos with a maximal scale value, they cannot provide an explanation for cases like (44). In this example, the telos cannot be equated with a maximal scale value and therefore a sentence like The independent counsel broadened the investigation significantly should result in an atelic predication.

The discussion of scalar approaches to telicity showed that intensifiers have an effect on the telicity of degree achievements. Change of state verbs that have an atelic interpretation have a telic reading if combined with intensifiers such as significantly. Hay et al. mention that such an effect only shows up with monotone-increasing intensifiers, whereas monotone-decreasing ones such as slightly do not make an atelic change of state predication telic (46).

(46) a. The independent counsel broadened the investigation slightly. (Hay et al., 1999, 134)

b. The independent counsel is broadening the investigation slightly. $\rightarrow$ The independent counsel has broadened the investigation slightly.

(Hay et al., 1999, 135)

18 For a critical examination of Caudal \& Nicholas' approach see Piñón (2008). 
Since monotone-increasing intensifiers affect telicity by bounding the difference value and introducing a lower bound that has to be reached, it is expected that sehr also has an effect on the telicity of degree achievements. I turn to this topic in the next section. In the degree-based analyses of telicity, discussed above, the telos of accomplishment predicates is equated with the maximum scale value. Therefore, such analyses give rise to the prediction that accomplishments should not be gradable by sehr. To explicate this prediction, the properties of accomplishments have to be taken into account:

Properties of accomplishments

(i) A telic change of state predication is true, if the telos is reached.

(ii) The telos is the maximal value on a scale.

Now we must take the properties of sehr into account (ii), which were discussed in chapter 5.3 .

\section{Properties of sehr}

(iii) Sehr is factive, it entails the truth of the embedded predication.

(iv) Sehr can only apply to predicates which truthfully denote at least two non-zero degrees.

Since the telos is taken to be the maximal scale value, it should be the case that accomplishments do not license sehr. The reason is that on the one hand sehr presupposes the truth of the predicate it applies to (in the case of accomplishments the reaching of the maximal scale value) and on the other hand sehr requires that the predicate it applies to truthfully denotes at least two degrees and not just a single one. As the telos is equated with the maximum degree, this should lead to ungradability of accomplishments by sehr. In the next section, I will turn to a detailed discussion of degree gradation of change of state verbs which will show that the view on telicity sketched above is too restrictive and needs revision. 


\subsection{Degree gradation of change of state verbs}

In this section, I will focus on degree gradation of change of state verbs. Degree achievements and accomplishments will be discussed separately since a degree-based account of telicity, which equates the telos with the maximal scale value, predicts that accomplishments should reject gradation by sehr. The following section is based on my discussion of degree gradation of change of state verbs in Fleischhauer (2013).

\subsubsection{Degree gradation of degree achievements}

Degree achievements, i.e. atelic uses of change of state verbs, are perfectly gradable by sehr. ${ }^{19}$ The sentences in (49) to (51) are naturally occurring examples. Please note, that the English translations make either use of different verbs - expand in (49) instead of widen - and/or use different intensifiers. It is a lot in (50) and (51) but greatly in (49).

Das Angebot der Pflege hat sich in den letzten Fahrzehnten in the offer of.the care has REFL in the last decades in Folge der immer weiter zerfallenden Kleinfamilien sehr course of.the ever further decaying nuclear families very verbreitert.

widened

'The range of care has expanded greatly over the last few decades as a consequence of the decay of the nuclear family. $G$

(50) Erst als ich die Vorlage sehr vergrößert hatte, konnte er den first when I the template very enlarged had could he the Text lesen.

text read

'It was not until I had enlarged the template a lot that he was able to read the text. $G$

$19 \quad$ Kriz $(2011,36 f$.$) mentions that degree achievements allow for the same degree mod-$ ifiers as adjectival comparatives and are only marginally acceptable with intensifiers of the positive form. But as shown in the examples, degree achievements do combine with sehr which does not apply to adjectival comparatives (see the discussion in chapter 2). 

Zu den Chancen einer kirchlichen Wiedervereinigung sagte to the chances a churchly reunification said Lehman: "Sie sind natürlich sehr gewachsen, wie noch nie in Lehmann they are naturally very grown like still never in der Geschichte vorher." the history before 'Speaking of the likelihood of a reunification of the churches, Lehmann said: "Of course, it has increased a lot, like never before".' $G$

In all three examples, the verbs are used in the perfect having a perfective interpretation and therefore expressing a completed situation. ${ }^{20}$ The effect of sehr is to specify the amount of change. Taking (50) as an example, the sentence without sehr (52) has the interpretation that the speaker merely had to make the template larger. Clearly, not any increase in size would be sufficient for a true predication. The template needs to be enlarged enough to become readable for the speaker, which indicates the contextdependency of the difference value for degree achievements. But even if the difference degree is context-dependent, it is not specified and therefore the predication is atelic. By adding sehr, it is specified that the speaker increased the size of the template by a contextually large amount.

$$
\begin{aligned}
& \text { Erst als ich die Vorlage vergrößert hatte, konnte er den Text } \\
& \text { first when I the template enlarged had could he the text } \\
& \text { lesen. } \\
& \text { read }
\end{aligned}
$$

'It was not until I had enlarged the template that he was able to read the text.'

As the contrast between (49), (51) and (50) shows, causativity does not affect degree gradation. In (50) we have a causative verb, whereas the verb in (51) does not have a causative variant and the one in (49) is a derived inchoative verb. In each case, it is the amount of change that is specified by

\footnotetext{
$20 \quad$ Note that wachsen 'grow' takes sein 'be' as a perfect auxiliary, whereas sich verbreitern 'widen' takes haben 'have', which is due to the presence of the reflexive in the latter case. Syntactically, reflexive verbs behave like transitive verbs and therefore build the perfect with haben as transitive verbs do.
} 
sehr. In (53a) the paraphrase of an ungraded but causative degree achievement is given. The paraphrase of a graded causative degree achievement is added in (b). As shown in (53b), the paraphrase indicates that gradation of degree achievements is very close to gradation of adjectival comparatives. This is also indicated by the choice of the intensifier in the paraphrase, which is viel in German and much in English. In (54), the paraphrases are applied to a concrete example, namely the causative use of vergrößern discussed in (50) and (52).

$$
\begin{aligned}
& \text { a. ungraded (causative) DA: 'ADJ-COMP machen' } \\
& \text { 'make ADJ-COMP' } \\
& \text { b. graded (causative) DA: 'viel ADJ-COMP machen' } \\
& \text { 'make much ADJ-COMP' }
\end{aligned}
$$

(54) a. vergrößern: 'größer machen' 'enlarge' 'make larger'

b. sehr vergrößern: 'viel größer machen' 'enlarge a lot' 'make much larger'

The semantic representation of a degree achievement has already been introduced in section 6.3 and is repeated in (55) for the verb vergrößern 'enlarge.'

$$
\begin{aligned}
& \llbracket \text { vergrößern } \rrbracket=\lambda \mathrm{x} \lambda e \cdot \operatorname{sizE}_{\langle\Delta, D, R<\rangle}(\mathrm{x}, \operatorname{BEgIN}(\mathrm{e}))<\operatorname{sizE}_{\langle\Delta, D, R<\rangle} \\
& (\mathrm{x}, \operatorname{END}(\mathrm{e}))
\end{aligned}
$$

Sehr, as discussed above, specifies the difference between the initial and the final degree but there is no explicit representation of this difference in (55). Therefore, I propose the equivalent representation in (56) which uses the DIFF function. DIFF returns the difference between the final degree on the price scale and the initial degree on that scale. The predication is true if the degree returned by the function is taller than zero.

$$
\begin{aligned}
& \llbracket \text { vergrößern } \rrbracket=\lambda \mathrm{x} \lambda \mathrm{e} \cdot \operatorname{DIFF}\left(\operatorname{size}_{\langle\Delta, D, R<\rangle}(\mathrm{x}, \operatorname{END}(\mathrm{e})),\right. \\
& \left.\operatorname{SIZE}_{\langle\Delta, D, R<\rangle}(\mathrm{x}, \operatorname{BEGIN}(\mathrm{e}))\right)>0
\end{aligned}
$$

The effect of sehr is now to further specify the difference between those degrees as represented in (57). As for the positive form of adjectives, sehr introduces a standard of comparison 's' which is calculated based on the 
positive - or in this case ungraded - predicate. Sehr vergrößern is true if the differential degree exceeds the standard based on the predicate vergrößern.

$$
\begin{aligned}
& \llbracket \text { vergrößern } \rrbracket=\lambda \mathrm{x} \lambda \mathrm{e} \cdot \operatorname{DIFF}\left(\operatorname{size}_{\langle\Delta, D, R<\rangle}(\mathrm{x}, \operatorname{END}(\mathrm{e})),\right. \\
& \operatorname{SIZE}_{\langle\Delta, D, R<\rangle}(\mathrm{x}, \operatorname{BEGIN}(\mathrm{e})) \geq \mathrm{s}\left(\operatorname { D I F F } \left(\operatorname{sizE}_{\langle\Delta, D, R<\rangle}(\mathrm{x}, \operatorname{END}(\mathrm{e})),\right.\right. \\
& \operatorname{siZE}_{\langle\Delta, D, R<\rangle}(\mathrm{x}, \operatorname{BEGIN}(\mathrm{e}))
\end{aligned}
$$

Similar examples to those discussed above can be found in Russian and French. Examples of graded degree achievements from Russian are shown in (58). Očen' indicates the degree of change in these examples as sehr does in German. The verbs in (58) are perfective, and I will turn later to a comparison with imperfective change of state verbs.
a. Očen'vy-rosli zolotye zapas-y. very VY-grew gold reserve-PL.NOM
'The gold reserves grew a lot.' $R$
b. Pribor očen' na-grel-sja. device.NOM very NA-heated-REFL 'The device heated up a lot.' $R$

French examples of graded degree achievements are shown in (59) to (61). Beaucoup indicates the degree of change in these examples; an extent reading of beaucoup is not possible in these cases.

(59) J'ai beaucoup grandi.

$\mathrm{I}=$ have a lot grown

'I have grown a lot.'

(60) Si mon état s'est beaucoup amélioré depuis quelques if my condition $\mathrm{REFL}=\mathrm{is}$ a lot improved since several mois $[\ldots]$. months $[\ldots]$

'If my condition has greatly improved over the last few months [...].' (Fleischhauer, 2013, 147) 


$$
\begin{aligned}
& {[. .] \text { cette perfide instabilité diminua beaucoup la }} \\
& {[. .] \text { this perfidious instability diminished a lot the }} \\
& \text { confiance et l'amitié que m'inspirait la nature. } \\
& \text { confidence and the=friendship that REFL=inspired the nature } \\
& \text { '[...] this perfidious instability has greatly diminished the confi- } \\
& \text { dence and friendship that nature inspired in me.' } \\
& \text { (Fleischhauer, 2013, 147f.) }
\end{aligned}
$$

The verbs in the examples discussed above lexically specify the scale but the verbs in (62) and (63) are underspecified with regard to the scale of change. In these cases, sehr specifies the amount of change, too. The sentence in (62) expresses that the price of oil has not only risen by some amount but to a contextually large amount. The change is measured on a price scale which is specified by the functional noun Preis 'price.' (63) also has the reading that there is a contextually 'large' difference between the initial and the final degree but Aussehen 'appearance' is not a scaledenoting noun and therefore does not induce a scale. Rather, sehr applies merely to an unspecified difference scale, which measures the difference between two states.

(62) Der Preis des Öls ist sehr gestiegen. the price of.the oil.GEN is very risen 'The price of oil has risen a lot.'

(63) Sein Aussehen hat sich sehr verändert. his appearance has REFL very changed 'His appearance changed a lot.'

Verbs like steigen and fallen have extensional as well as intensional uses. In their intensional use, they denote a change of state and the respective scale is contributed by a functional noun. In their extensional use, these verbs denote a change of location. Steigen expresses an upward movement, whereas fallen denotes a downward movement. Following Fleischhauer \& Gamerschlag (2014), I assume that extensional steigen expresses an increase with respect to the vertical location of an object, which means that the scale is lexically specified by the verb and measures the height of an object. The scale does not measure a property of the object as such but a path along which the object moves. Both, the intensional (62) as well as the 
extensional use (64) can be graded by sehr. (64) has the interpretation that the height at which the object is located increased by a large amount.

$$
\begin{aligned}
& \text { Der Ballon ist sehr gestiegen. } \\
& \text { the balloon is very risen } \\
& \text { 'The balloon rose a lot.' }
\end{aligned}
$$

In constructions such as die Treppen steigen 'climb the stairs,' extensional steigen rejects gradation by sehr (65). Die Treppen steigenexpresses an upstairs movement, combining direction and manner (see Gamerschlag et al. 2014 for a more detailed discussion of the differences between the extensional, the intensional as well as the manner use of steigen and a framebased analysis of these uses). Gradation may be rejected since stairs have a natural end, whereas steigen in sentences as (64) expresses an upward movement without a linguistically specified endpoint.

$$
\begin{aligned}
& \text { *Ich bin die Treppen sehr gestiegen. } \\
& \text { I am the stairs very risen }
\end{aligned}
$$

In its extensional use fallen expresses a downward movement of the referent of the theme argument. The ground provides a natural endpoint for extensional fallen and sehr cannot be used to specify the change of the position of the theme argument. Nevertheless, as (66) shows, fallen can be graded by sehr; the sentence has the interpretation that the boy fell hard and not that the height at which the boy is located decreased by a large amount. Sehr specifies the effect of fallen on the boy, indicating that he hurt himself badly. Such a gradation construction is only possible with animate subjects and not with inanimate ones such as *Der Ball ist sehr gefallen 'The ball fell very hard.'

$$
\begin{aligned}
& \text { Der funge ist sehr gefallen. } \\
& \text { the boy is very fallen } \\
& \text { 'The boy fell hard.' }
\end{aligned}
$$

For downward movement, there is a different verb sinken 'sink, fall' which can be used for an extensional description of a decrease of height (67). The example shows that the verb can be graded in its extensional use, indicating that a large decrease in height occurred. The difference between sinken and 
extensional fallen is that only the latter expresses a motion to the ground and therefore only fallen comes with a natural endpoint. In (64) and (67), the respective scale is a path rather than a property scale.

$$
\begin{aligned}
& \text { Der Ballon ist sehr gesunken. } \\
& \text { the ballon is very sunk } \\
& \text { 'The balloon fell a lot.' }
\end{aligned}
$$

Before I turn to accomplishments, the question whether grammatical aspect affects degree gradation needs to be discussed. In (68), the verb wachsen is used in a perfect (a) and a progressive construction (b). In (a), it is expressed that the size of the child increased by a contextually large amount. What is specified is the total amount of change accomplished in the event. This is different for (b) as the event is described as ongoing with respect to the reference time. The progressive aspect picks out one of the subevents of the whole event denoted by wachsen and specifies the degree of change at this subevent. We get the interpretation that at a certain part of the event, the size of the child increased a lot. This does not entail that in the total event the size increased a lot. The reverse does not hold either: if the size increased a lot over the entire course of the event, it does not entail that there was a large increase during any specific one of its subevents.
a. Das Kind ist sehr gewachsen. the child is very grown 'The child has grown a lot.'
b. Das Kind ist sehr am Wachsen. the child is very at.the growing 'The child is growing a lot.'

The effect of sehr is the same in the progressive as well as the perfectively interpreted perfect construction, namely specifying the degree of change. It is grammatical aspect that leads to the differences in the interpretation between (68a) and (b). Following Filip $(1999,172)$, we can assume a semantic representation for the progressive operator as shown in (69). The progressive restricts the predicate to a subevent. Since a subevent also has a beginning and an ending, we can specify the degree of change between these two moments. And this is what we find in a case like (68b). 


$$
\text { PROGRESSIVE }=\lambda \mathrm{P} \lambda \mathrm{e}^{\prime} \exists \mathrm{e}\left[\mathrm{P}(\mathrm{e}) \wedge \mathrm{e}^{\prime} \leq \mathrm{e}\right](\text { Filip, 1999, 172) }
$$

This analysis fits the view that grammatical aspect has scope over degree gradation. First, sehr applies to the degree achievement and specifies the degree of change, then grammatical aspect is applied to the verb and either restricts the predication to a subevent - in the case of the progressive aspect - or to the total event if the verb is interpreted perfectively.

For Russian, we see the same difference as observed in German. In (70a), we have the perfective verb vyrasti 'grow' and in (b) the corresponding secondary imperfective vyrastat'. Like in (68), we see a difference between the indication of the total amount of change in (70a) and the specification of the degree of change at an instance of the event (b).
a. Rebënok očen'vyros.
child.NOM very grew
'The child has grown a lot.'
b. Rebënok očen' vyrastal.
child.NOM very grew
'The child was growing a lot.'

\subsubsection{Degree gradation of accomplishments}

In section 6.4, it was stated that accomplishments should not be gradable since the requirement of reaching the telos leads to an incompatibility with intensifiers like sehr. But contrary to this expectation, telic change of state verbs can be graded by sehr (71). As was the case for degree achievements, English does not make use of one and the same intensifier with all these verbs. Rather it uses a lot in (a) but very much in the other two examples (b/c). The examples in (71) are collected from Sebastian Löbner's database. However, speakers do not usually reject gradation of accomplishments in general but only single examples.

a. In der Sonne trocknen Nacktschnecken sehr aus. in the sun dry slugs very out 'Slugs dry out a lot in the sun.' $G$

b. Die Verhältnisse haben sich wieder sehr normalisiert. the circumstances have REFL again very normalized 'The circumstances have very much normalized again.' $G$ 
c. Man könnte die beiden Gruppen noch sehr vereinheitlichen. one could the both groups still very standardize 'One could still standardize both groups very much. ${ }^{,}$

Before we consider the interpretation of degree gradation in cases like those in (71) in detail, it has to be shown that the ungraded verbs are telic. Taking the verb normalisieren 'normalize' as an example, (72) shows an ambiguity with the adverb fast 'almost.' The adverb either indicates that the event has almost started or that it has almost finished, as it is typical for telic predications.

\section{Die Verhältnisse haben sich fast normalisiert. the circumstances have REFL almost normalized 'The circumstances have almost normalized.'}

The sentence in (72) merely indicates that the ungraded verb is telic but does not allow inferring whether the graded verbs are telic too. It could be the case that the presence of the intensifier requires a coercion of a telic to an atelic predication. The time-span adverbial in kurzer Zeit 'within a short time' in (73) specifies the time it took to reach the telos in this case the state of being very stable. This shows that the graded sentence in (73) is telic like the ungraded verb in (74), too.

If one assumes that telic predicates are related to closed scales, then two different strategies to explain the data are possible. First, one could assume that the application of sehr requires a shift from a closed scale to an open scale predication, which would also entail a shift from a telic to an atelic predication. By application of sehr, the shifted atelic predicate would again be shifted to a telic predicate since the graded predicate is telic. This argumentation is in accordance with the assumption that sehr can only apply to open scale predicates but it requires two steps of coercion. A second option would be to simply assume that sehr can also apply to closed scale predicates. This would not require coercion and therefore is the more parsimonious assumption. But this second option is not compatible with the view that the telos is a maximal scale value. In section 6.6, I will argue for the second option and present an analysis of telicity that does not require a telos to be (always) a maximal scale value. 
Ich kam sehr instabil auf die Station [...] Dennoch wurde ich in I came very instable on the ward however become I in kurzer Zeit sehr stabilisiert.

short time very stabilized

'In was in a very unstable condition when I arrived on the ward [... but my condition stabilized a lot within a short time. ${ }^{, 21}$

Der Zustand des Patienten hat sich in kurzer Zeit stabilisiert. the condition of.the patient has REFL in short time stabilized 'The condition of the patient stabilized within a short time.'

Degree gradation of accomplishment predicates leads to a specification of the result state. In sentences like those in (71) and (73) the intensifier indicates the degree of the result state, so if something stabilisiert sich sehr 'stabilizes a lot,' as in (73), it becomes 'very stable,' meaning stable to a high degree. Whereas the ungraded sentence (74) merely expresses that the referent of the theme argument becomes stable but not necessarily to a high degree since any degree of stability is sufficient.

A paraphrase for ungraded and non-causative accomplishments is given in (75a). Contrary to degree achievements it is not a comparative but an absolute result state that is achieved which, in German and English, at least in some cases, is denoted by an adjective. The paraphrase for graded accomplishments is given in (75b).
a. ungraded accomplishment: 'ADJ ${ }_{P O S}$ werden' 'Become $\mathrm{ADJ}_{P O S}$ '
b. graded accomplishment: 'sehr $\mathrm{ADJ}_{P O S}$ werden' 'Become very ADJPOS'

As can be seen, degree gradation of accomplishments differs from degree gradation of degree achievements. In the case of degree achievements, sehr indicates the amount of change, i.e., the difference between the initial and the final degree. In the case of accomplishments, sehr does not bind a difference value, but provides a further specification of the resulting state. Since accomplishments are telic, there is already some degree up to which the change has (at least) to progress - the telos. Gradation by sehr indicates

21 http://www.klinikbewertungen.de/klinik-forum/erfahrung-mit-krankenhauserlangen?bew_order=1\&fac_id=psysom 
that the change did not stop at the telos but progresses further till a 'high' degree of the resulting state has been achieved.

Based on the semantic representation of degree achievements, I propose the representation in (76) for accomplishments. For these predicates, a conjunct is added that represents the result state. The degree for the result state is equated with the telos, represented by ' $\mathrm{d}_{\text {telos }}$ '. The telos is lexically indicated and therefore specified by the verb, but as I will show later, the telos is not always the maximal scale value. In the case of degree gradation, the intensifier further specifies the degree of the result state, as shown in (77) for sich sehr stabilisieren 'stabilize a lot.'

$$
\begin{aligned}
& \lambda \varphi \lambda \mathrm{x} \lambda \mathrm{e} \cdot \varphi(\mathrm{x}, \operatorname{BEgin}(\mathrm{e}))<\varphi(\mathrm{x}, \operatorname{End}(\mathrm{e})) \wedge \varphi(\mathrm{x}, \operatorname{End}(\mathrm{e})) \geq \mathrm{d}_{\text {Telos }} \\
& \llbracket \operatorname{sehr} \text { stabilisieren } \rrbracket=\lambda \mathrm{x} \lambda \text { e.STABILITy }(\mathrm{x}, \operatorname{BEGIN}(\mathrm{e}))<\operatorname{stability}(\mathrm{x}, \\
& \operatorname{End}(\mathrm{e})) \wedge \operatorname{stability}(\mathrm{x}, \operatorname{END}(\mathrm{e}))=\operatorname{high}
\end{aligned}
$$

Why does sehr take the second but not the first conjunct of the formula as its argument? The answer is that in the case of accomplishment predicates the degree of change is always specific as it is the difference between the initial degree and the telos. A double specification of the difference degree is not possible and therefore sehr cannot specify the amount of change directly. Rather, it modifies the result state and thereby indirectly indicates the amount of change. This coincides with the fact that degree gradation by sehr is not possible if the difference degree is explicitly bound by a measure phrase as in (78).
a. Das Kind ist zehn Zentimeter gewachsen. the child is ten centimeters grown 'The child has grown ten centimeters.'
b. *Das Kind ist zehn Zentimeter sehr gewachsen. the child is ten centimeters very grown

We also find graded accomplishments in Russian and also French: in (79) to (81) Russian examples are shown; French examples are listed in (82) and (83). The interpretation of these examples is the same as for the German cases, the intensifiers specify the degree of the resulting state. 


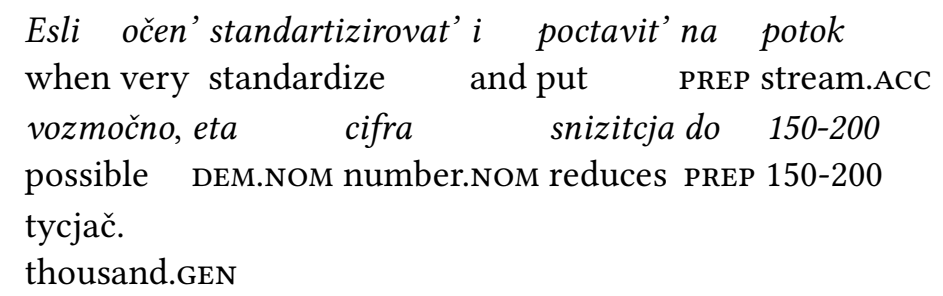

(80) Sejčas my provodim konsul'tacii s tem, čto now 3PL.NOM conduct consultations.ACC with DEM.INST what vce-taki očen' unificirovat' tarify konsul'skix sborov ultimately very unify rate.ACC consular.GEN tax.GEN.PL 'At the moment we are negotiating with the aim of standardizing the consultant fares very much' $R$

(81) 1-oe, čto nužno sdelat' očen' stabilizirovat' sostojanie first what need make very stabilize condition.ACC bol'nogo $[. .$.$] .$ ill.gEN 'The first thing that needs to be done is to stabilize the condition of the injured a lot [...]. $R$

(82) [...] et le lexique c'est beaucoup standardisé en $[. .$.$] and the lexicon \mathrm{DEM}=\mathrm{is}$ a lot standardized by s'alignant sur le haut-allemand de l'école et des REFL=adapting to the high-German PREP the $=$ school and PREP medias.

media

'[...] and the lexicon has been mostly standardized by being adapted to High German in school and in media.' (Fleischhauer, 2013, 148) 


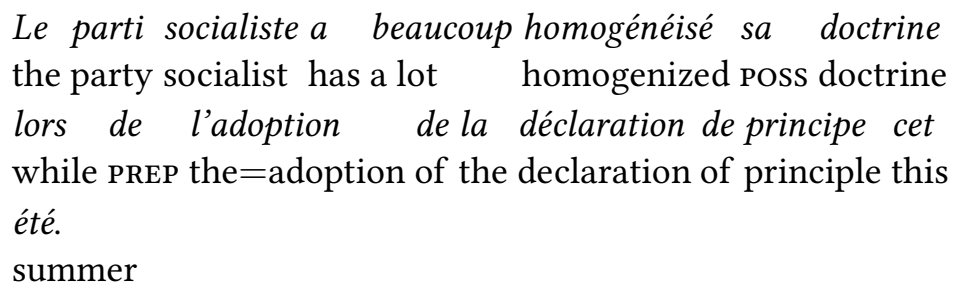

'The socialist party has greatly unified by adopting the principle declaration this summer.'22

The Russian verbs in (79) to (81) are biaspectual, they allow either for a perfective or an imperfective reading. In German, accomplishments can be used in the progressive (84a) but this construction sounds somewhat odd if combined with an intensifier. Most German native speakers I consulted rejected sentences like (84b). Degree gradation of telic predicates is dispreferred if the predicate is used in an explicit progressive construction. The reason is that the result state is canceled by the progressive aspect and therefore the target of sehr is not accessible.
a. Sein Zustand ist sich am Stabilisieren.
his condition is REFL at.the stabilizing
'His condition is stabilizing.'
b. ??Sein Zustand ist sich sehr am Stabilisieren.
his condition is REFL very at.the stabilizing

\subsection{Degree gradation and telicity}

In the last section, I discussed degree gradation of degree achievements as well as accomplishments. I showed that both types of change of state verbs can be graded, which, for accomplishments at least, is unexpected. In this section, I will turn to a discussion of the interaction of telicity and degree gradation in change of state verbs. Two different questions arise: first, does degree gradation of degree achievements interact with telicity? And second, how can it be that (some) accomplishments admit degree gradation?

Starting with degree achievements, Hay et al. (1999) argue that monotone-increasing intensifiers affect their telicity. This effect is found

22 http://www.france24.com/fr/20081125-je-pense-pas-quune-scission-ps-soit-possibleparti-socialiste?quicktabs_1 $=0 ; 21.08 .2013$ 
with sehr, too (85). Wachsen 'grow' is strictly atelic, but gets a telic reading if graded by sehr. A lot has the same effect on grow, as the English translation of the example shows.
a. \#Das Kind ist in einem Fahr gewachsen. the child is grown in one year 'The child has grown in one year.'
b. Das Kind ist in einem fahr sehr gewachsen. the child is in one year very grown 'The child has grown a lot in one year.'

The same holds for Russian, as the examples in (86) show. The verb vyrastat' 'grow' is atelic and as (b) shows, the intensifier licenses a telic interpretation of the predication.
a. \#Rebënok vyrastal za odin god. child.Nom grew in one year 'The child has grown in one year.'
b. Rebënok očen'vyrastal za odin god. child.NOM very grew in one year 'The child has grown a lot in one year.'

Caudal \& Nicolas (2005) discuss similar examples and argue that verbs like run have an implicit quantity argument that can be bound by a lot. Sentence (87a) is atelic, whereas (b) is telic and a lot specifies the distance of the running. ${ }^{23}$ The only difference is the intensifier $a$ lot in (b). The authors write: " $A$ lot apparently requires an open scale as its input, and yields a closed one as its output (cf. the telic predication Yannig ran a lot in $\left({ }^{*}\right.$ for) two hours)" (Caudal \& Nicolas, 2005, 284).
a. Yannig ran (for a long time).
b. Yannig ran a lot.

(Caudal \& Nicolas, 2005, 284)

A crucial assumption of Caudal \& Nicolas seems to be that if a graded predication is telic, the intensifier closes the scale. They write, with regard to a

23 There is also a frequency interpretation of the sentence, which is irrelevant for the current discussion. 
similar example to the one in (87b), "the addition of a lot renders the scale closed" (Caudal \& Nicolas, 2005, 288). This is based on the assumption that telic predications are always related to closed scales. However, all we can see is that the predication is telic but not that the scale is closed. The usual tests that are used to determine whether a scale is open or closed cannot be applied to (87b) but it is possible to say Yannig already ran a lot and he is still running which indicates that it is possible to further increase the distance Yannig ran. ${ }^{24}$ Departing from Caudal \& Nicolas and in accordance with Hay et al. (1999), I assume that a predication can be telic, even if the scale is not closed. Sehr but also a lot do not specify a fixed degree on a scale; rather they introduce a lower bound which has to be attained. Hence, the presence of a closed scale is a sufficient but not a necessary criterion for telicity.

I will now turn to the second question, namely why (at least some) accomplishments allow degree gradation. Caudal \& Nicolas' definition of telicity, discussed in section 6.4, and similar accounts, predict that accomplishments are not gradable. This is contrary to the data discussed in 6.5.2, which show that accomplishments admit degree gradation. To account for these data, a more fine-grained distinction of types of telos is necessary. Following Kearns (2007), two types of telos can be distinguished - a maximum and a standard telos. A maximum telos can be equated with a maximal scale value and therefore coincides with the endpoint of a scale. A standard telos is a nonmaximal scale value that marks the onset of a result state. Maximum and standard telos are distinct if an accomplishment entails a result state that is not a single value on a scale, but covers a set of values. If the result state is a single scale value, standard and maximum telos coincide. Caudal \& Nicolas' definition of telicity only covers the notion of a maximal telos.

To distinguish between both types of telos, Kearns introduces two test criteria. The first one tests whether the transition to a maximal degree can be negated without contradiction. If this is the case, the achievement of a maximal degree is merely an implicature but not entailed. As (88a) shows, the attainment of the result state cannot be negated without contradiction. But it is not contradictory to negate the transition to a maximal degree, i.e., to say that something stabilized but did not become completely stable

$\overline{24}$ I am thankful to Robert D. Van Valin, Jr. for bringing up this example. 
(88b). Stabilisieren describes a transition to a telos which is not necessarily a maximal scale value.

a. \#Der Zustand hat sich stabilisiert, er ist aber nicht stabil. the condition has REFL stabilized he is but not stable 'The condition has stabilized, but it is not stable.'

b. Der Zustand hat sich stabilisiert, er ist aber nicht the condition has REFL stabilized he is but not vollkommen stabil. completely stable 'The condition has stabilized, but it is not completely stable.' (Fleischhauer, 2013, 141)

The second test criterion asks whether it is possible that the result state is achieved but still higher degrees could be attained. Therefore, I use the test frame $X$ had $V$-ed, but could still be more $A D \mathcal{f}$, whereby $A D \mathcal{f}$ denotes the result state of the verb. If a verb can be used in such a test frame, it is related to a standard telos. Otherwise, the attainment of higher degrees should not be possible. Stabilisieren can be used in the test frame without a contradiction (89); something can be stabilized but still become more stable.

$$
\begin{aligned}
& \text { Der Zustand des Patienten hat sich stabilisiert, er könnte } \\
& \text { the condition of.the patient has REFL stabilized he could } \\
& \text { aber noch stabiler sein. } \\
& \text { but still more stable be } \\
& \text { 'The physical condition of the patient has stabilized, but it could } \\
& \text { still be more stable.' (Fleischhauer, 2013, 141) }
\end{aligned}
$$

As (90) shows, the verb schließen 'close' leads to a contradiction if used in the test frame. The verb is related to a maximum telos which excludes the possible attainment of a higher degree.

(90) \#Peter hat die Tür geschlossen, sie könnte aber noch geschlossener Peter has the door closed she could but still more closed sein.

be

'Peter has closed the door, but it could still be more closed.' (Fleischhauer, 2013, 141) 
Only accomplishment change of state verbs related to a non-maximal standard telos license degree gradation. Stabilisieren is gradable by sehr, as demonstrated in the last section, and as the two tests discussed above reveal, it has a distinct standard telos. Schließen, which, as demonstrated above, does not have a distinct standard telos, is also not gradable by sehr (91).

(91) \#Peter hat die Tür sehr geschlossen.

Peter has the door very closed

The distinction between standard and maximum telos allows a prediction which accomplishments admit degree gradation and which reject it. Only those related to a standard telos admit it; those without a distinct standard telos reject it (see Fleischhauer 2013 for cross-linguistic testing of this prediction). The explanation for this is straightforward, since sehr requires that the predicate it modifies truthfully denotes a set of degrees and not only a single one. A standard telos marks the onset of an extended result state and it is the minimal degree that has to be achieved to yield a true predication. If an accomplishment does not have a distinct standard telos, its result state only covers a single point on the scale, which does not fit with the requirement of sehr. As a consequence, a telos is not necessarily the endpoint of a scale but any lower bound that has at least to be reached to yield a true predication. Therefore, Caudal \& Nicolas' definition of telicity must be reformulated. It is given in (92).

Telicity: A predication is telic if and only if,
a. it has an associated range of degrees with,
b. a specified standard value, and
c. its verbal predication satisfies axiom Весоме [...] (Fleischhauer 2013, 142, slightly changed)

The crucial part of the reformulated definition is that a predication is telic if there is some specified standard value which has to be reached. This means that some lower bound up to which the change has to progress has to be specified. This is also the explanation Hay et al. present for the fact that monotone-increasing intensifiers lead to a telic reading of a degree achievement, whereas monotone-decreasing ones do not. They state: "a telic reading of a DA [degree achievement] requires that the difference 
value specify a lower bound on the degree to which an object must increase in the relevant property over the course of the event" (Hay et al., 1999, 134). Slightly, which is monotone-decreasing, does not introduce a lower bound and therefore does not lead to a telic predication.

Different types of predications are related to different types of telos. A degree achievement does not have any telos, it is atelic. Graded degree achievements, i.e., achievements that are modified by a degree expression like sehr, are telic, as shown above. The telos is determined by the intensifier. Ungradable accomplishments are only related to a maximum telos, whereas gradable ones entail a standard telos and implicate a maximum telos. ${ }^{25}$ Graded accomplishments, i.e., accomplishments that are modified by a degree expression like sehr, are telic, and it cannot be demonstrated that they differ with regard to telicity from gradable accomplishments. Table 15 summarizes the different types of predicates and the types of telos associated with these verbs.

\begin{tabular}{|l|l|}
\hline Type of predication & Type of telos \\
\hline degree achievement & no telos (= atelic) \\
\hline graded degree achievement & $\begin{array}{l}\text { derived standard telos (= standard induced by } \\
\text { sehr) }\end{array}$ \\
\hline ungradable accomplishment & maximum telos \\
\hline gradable accomplishment & $\begin{array}{l}\text { standard telos (entailed) and maximum telos } \\
\text { (implicated) }\end{array}$ \\
\hline graded accomplishment & like 'gradable accomplishment' \\
\hline
\end{tabular}

Table 15: Types of predicates and their associated types of telos (Fleischhauer, 2013, 142).

It is an open question whether gradable accomplishments always implicate a maximum telos. It seems that at least some verbs, such as stabilisieren, normalisieren 'normalize' and austrocknen 'dry out,' do. The reason for this assumption is that these verbs license endpoint intensifiers (93), which presuppose, following Kennedy \& McNally (2005a), an endpoint of a scale.

$25 \quad$ Ungradable means 'not gradable by sehr.' Correspondingly, I restrict the notion of 'gradable accomplishments' to those that admit degree gradation by sehr. 
a. Der Zustand hat sich vollständig stabilisiert. the condition has REFL completely stabilized 'The condition has completely stabilized.'

b. Die Situation hat sich vollständig normalisiert. the situation has REFL completely normalized 'The situation has completely normalized.'

c. In der Sonne trocknen Nacktschnecken vollständig aus. in the sun dry slugs completely out 'Slugs dry out completely in the sun.'

(Fleischhauer, 2013, 143)

Adopting the semantic representation of accomplishments proposed in the last section, I assume two different semantic representations for gradable (94a) and ungradable accomplishments (b). The only difference is in the degree of the attained result state. For an ungradable accomplishment, which is related to a maximal telos, the reaching of the result state entails that the maximal degree on the scale is attained. For gradable accomplishments, it is merely entailed that the result state holds to a degree which is equal or larger than the standard telos.
a. $\lambda \varphi \lambda \mathrm{x} \lambda \mathrm{e} . \varphi(\mathrm{x}, \operatorname{BEgIN}(\mathrm{e}))<\varphi(\mathrm{x}, \operatorname{END}(\mathrm{e})) \wedge \varphi(\mathrm{x}, \operatorname{END}(\mathrm{e}))=$ $\mathrm{d}_{\text {MaxTelos }}$
b. $\quad \lambda \varphi \lambda \mathrm{x} \lambda \mathrm{e} . \varphi(\mathrm{x}, \operatorname{BEGIN}(\mathrm{e}))<\varphi(\mathrm{x}, \operatorname{END}(\mathrm{e})) \wedge \varphi(\mathrm{x}, \operatorname{END}(\mathrm{e})) \geq$ $\mathrm{d}_{\text {StandardTelos }}$

The data presented above reveal that gradable accomplishments are closed scale predicates and therefore the assumption that sehr is only compatible with open scale predicates is too strong. Sehr can intensify closed scale predicates as long as they denote a set of values on a scale and not merely a single scale value.

\subsection{Conclusion}

This chapter provided a discussion of degree gradation of change of state verbs. The discussion revealed that there are differences between degree achievements and accomplishments regarding degree gradation. In the case of degree achievements, sehr specifies the amount of change but it is 
the result state that is modified in the case of graded accomplishments. For degree achievements, the facts that they admit degree gradation and also that monotonic-increasing intensifiers lead to a telic reading of otherwise atelic predications are uncontroversial.

For many degree-based accounts of telicity, degree gradation of accomplishments should be impossible. The treatment of a telos as a maximum scale value excludes the possibility for attaining a higher degree than the telos. Several examples from German, Russian and French showed that some accomplishments are gradable which led to a distinction between two types of telos.

Telicity turned out to be a relevant property affecting degree gradation. A different property of change of state verbs, namely whether the scale is fully specified in the verb's lexical semantics or not, does not affect degree gradation. There is a straightforward explanation for this fact. All change of state verbs are scalar but some do not fully specify the scale. Nevertheless, the expression of a scalar change builds the semantic core of these verbs and therefore is able to specify the obtaining difference on an unspecific scale.

The whole chapter centered on durative change of state verbs and I have not discussed degree gradation of punctual change of state verbs (achievements in the sense of Vendler). It seems that speakers reject degree gradation of punctual change of state verbs, at least if the theme argument denotes a single entity rather than a plurality or collection of things. As these verbs seem to reject degree gradation, I excluded them from the discussion. In the next chapter I will show that punctuality is not incompatible with degree gradation. 